SALÃO DE

INICIAÇÃO CIENTIFICA

XXIX SIC

S)

UFRES

PROPESQ

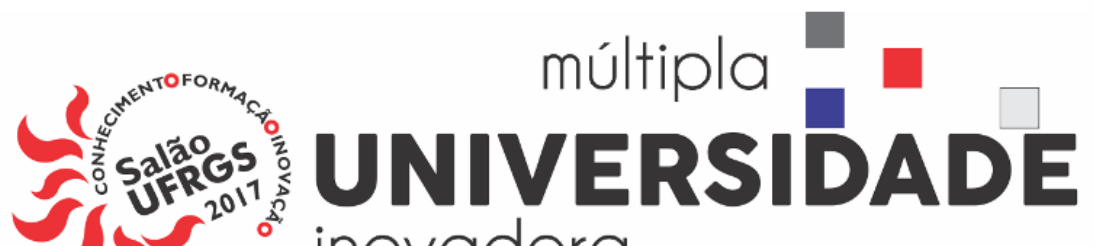

inovadora

\begin{tabular}{|l|l|}
\hline Evento & $\begin{array}{l}\text { Salão UFRGS 2017: SIC - XXIX SALÃO DE INICIAÇÃO } \\
\text { CIENTÍFICA DA UFRGS }\end{array}$ \\
\hline Ano & 2017 \\
\hline Local & Campus do Vale \\
\hline Título & Simulação de Espectrometria de Massa de Íons Secundários \\
\hline Autor & GABRIEL DOS SANTOS ONZI \\
\hline Orientador & PEDRO LUIS GRANDE \\
\hline
\end{tabular}




\title{
Simulação de Espectrometria de Massa de Íons Secundários
}

\author{
G. S. Onzi, I. Alencar, G. G. Marmitt, P. L. Grande \\ Instituto de Física, Universidade Federal do Rio Grande do Sul (UFRGS), CP 15051 Porto Alegre-RS, Brazil \\ gabrielonzi@gmail.com
}

Espectrometria de massa de íons secundários (SIMS) é uma poderosa técnica para se analisar a composição de superfícies sólidas dos materiais [1]. Nessa técnica, íons secundários são debastados do material alvo por um feixe de íons primário com massa e energia bem definidos num processo conhecido como sputtering. O uso de feixes primários com alta energia (MeV) em comparação com baixas energia (keV) diminui a fragmentação de moléculas e aumenta a quantidade de material ejetado [2]. Para a detecção dos íons secundários, pulsos de alta voltagem extraem tais íons para um tubo aterrado (livre de campo elétrico) onde uma lente eletrostática os direciona para o detector após passarem por um espelho eletrostático. O tempo percorrido desde o pulso de extração até a detecção é medido com resolução abaixo de nano-segundo. Uma nova linha para MeV-SIMS foi recentemente implementada no Laboratório de Implantação Iônica [3]. Com o intuito de compreender os fenômenos observados com o uso de feixes primários contínuos, criamos uma ferramenta para realização de simulações computacionais da técnica de SIMS. Nessa ferramenta, utilizamos conceitos de básicos de física (mecânica e eletromagnetismo) com integrações simples de velocidade e distância para calcularmos o tempo de vôo das partículas ejetadas. Dividimos o experimento em cinco principais etapas: 1. extração; 2. livre-deslocamento, 3/4. espelho eletrostático de duplo estágio; e 5. livre-deslocamento. Em cada uma dessas etapas, o tempo de vôo de cada partícula é calculado. Os valores obtidos na primeira região coincidem com a previsão. Pelo fato de a primeira etapa possuir cálculos mais laboriosos, esperamos bons resultados para a total implementação do algoritmo. O produto final seria um software capaz de simular o experimento para diferentes materiais e obter o ângulo sólido de coleção do instrumento. Por não haver atualmente softwares para simulação de SIMS abertamente disponíveis, seria interessante, também, prover essa ferramenta online para a comunidade acadêmica.

\section{Referências.}

[1] Vickerman, Analyst 136 (2011) 2199.

[2] Nakata et al., Appl. Surf. Sci. 255 (2008) 1591.

[3] Alencar et al., in prep. 